\title{
Amores prohibidos y anhelos de manumisión: las negras esclavas amantes de sus amos y su intrincada lucha por la libertad ${ }^{*}$
}

\author{
Roger Pita Pico ${ }^{* *}$ \\ Recibido: 1 de agosto de 2016 \\ Enviado a pares evaluadores: 9 de agosto de 2016 \\ Aprobado por pares evaluadores: 5 de septiembre de 2016 \\ Aprobado por Comité Editorial: 19 de septiembre de 2016 \\ DOI: 10.22395/csye.v5n10a1
}

\section{RESUMEN}

En el marco de las relaciones amorosas entre amos y esclavas ocurridas en el Nuevo Reino de Granada durante el período de dominio hispánico, el presente artículo tiene por objeto analizar la problemática que giró en torno a la incesante lucha de estas mujeres en lograr que se les cumpliera la promesa de libertad tanto para ellas como para los descendientes de esas uniones amorosas. Los casos descritos dejan al descubierto las inmensas complicaciones que debieron afrontar estas mujeres en medio de una sociedad tradicionalmente patriarcal y fuertemente permeada por los principios morales pregonados por el catolicismo. Pero, aún con todas las dificultades, resulta realmente destacable el valor y la decisión con que ellas buscaron reivindicar sus derechos sentimentales y su derecho a la libertad.

Palabras clave: esclavas; amos; relaciones amorosas; manumisión; Colonia; Nuevo Reino de Granada.

El artículo presentado hace parte de una investigación más amplia titulada Las relaciones amorosas entre blancos y negras esclavas en el Nuevo Reino de Granada durante el período colonial, la cual realizó el investigador con recurso propios entre 2013 y 2016.

** Magíster en Estudios Políticos de la Pontificia Universidad Javeriana, especialista en Gobierno Municipal y Política Social de la referida Universidad y politólogo de la Universidad de los Andes. Director de la Biblioteca Eduardo Santos de la Academia Colombiana de Historia. Correo electrónico: rogpitc@hotmail.com 


\section{Forbidden Love and Longings of Manumission: Amours of Slave Women with their Masters and their Intricate Struggle for Freedom}

\section{ABSTRACT}

In the context of loving relationships between masters and slave women occurred in the New Kingdom of Granada during the Hispanic domain, this article aims to analyze the problems revolved around the incessant struggle of these women to obtain the freedom both her and the descendants of that union. The cases described expose the immense complications that these women had to face in the midst of a traditionally patriarchal society and strongly permeated by moral principles touted by Catholicism. But even with all the difficulties, it is really remarkable courage and determination with which they sought to claim their sentimental rights and their right to freedom.

Keywords: slave women; masters; loving relationships; manumission; Colonial period; New Kingdom of Granada. 


\section{Introducción}

Durante el período de dominio hispánico, en el Nuevo Reino de Granada, la población esclava se asentó fundamentalmente en la costa Caribe y en el occidente en territorios de Antioquia, Chocó y Popayán (Jaramillo, 1989, p. 12). Una menor proporción se ubicó en otras zonas del interior y en la franja nororiental.

En el siglo XVIII los esclavos alcanzaron su máxima presencia en territorio neogranadino, principalmente vinculados a sectores vitales de la economía, tales como la minería, la ganadería y la producción de mieles (Jaramillo, 1989, p. 11). Según el censo levantado en 1778, esta comunidad representaba el $7.8 \%$ del total de la población, mientras que el mestizaje se hacía más que evidente al encontrarse un $46.5 \%$ de los llamados "libres" o "gentes de varios colores", seguidos en número por la gente blanca que aglutinaba a la cuarta parte del total. Por su lado, los indios mostraban un serio descenso del cual nunca volverían a recuperarse, con un 20 \% aproximadamente (Tovar, 1994, pp. 86-88).

Las relaciones entre amos y esclavas fueron complejas y diversas, algunas de las cuales trascendieron mucho más allá del simple esquema de dominación. Dentro de ese amplio espectro de posibilidades, se pudieron observar extremos que oscilaban entre intrincadas rivalidades y odios acérrimos hasta expresiones de afecto fraternal y vínculos amorosos ${ }^{1}$.

El afecto y la gratitud que el amo le profesaba a su esclava ${ }^{2}$ no solo se vio reflejado en su determinación de conferirle la libertad sino que, además, su preocupación lo llevó en algunos casos a asegurarle un mejor futuro económico, prodigándole mejores condiciones de subsistencia. Estas manifestaciones de estimación fueron encontradas, sobre todo, en las cartas testamentarias.

Por su parte, las esclavas intuyeron en este tipo de vínculo la posibilidad de escalar en el proceso de blanqueamiento. En una relación entre componentes étnicos disímiles, era comprensible esperar que los de baja condición buscaran relacionarse sexualmente con alguien de estatus superior como una fórmula para avanzar socialmente, en procura de beneficiar también a los posibles descendientes de esa unión.

En efecto, en algunas áreas del interior, como Santa Fe, Tunja, Antioquia y la franja nororiental, caracterizadas por una prolífica presencia de gentes blancas y mestizas, fue evidente e incontenible el proceso de blanqueamiento afrontado

1 En este tipo de relación "desigual" primó la imagen que el hombre blanco tenía acerca de la mujer negra y su propensión al pecado (Bermúdez, 1992, p. 78), (Escalante, 1964, p. 138).

2 En el contexto hispanoamericano, la temática sobre la vida sentimental y las relaciones interétnicas ha adquirido un auge en las últimas décadas. Para el caso colombiano, véase Rodríguez (1997), Tovar (2004). 
por el negro, principalmente desde el siglo XVIII. En los censos demográficos y en los archivos notariales de estas áreas fue cada vez más frecuente detectar alusiones fenotípicas que denotan ese acelerado mestizaje: "mulato blanco", "mulato rubio", "ojos claros", "blanquizco", "moreno claro", "color amarillo", "pelo liso", etc.

Pero, el problema radicaba en que la Corona y la Iglesia católica fueron inexorables en su decisión de no consentir este tipo de mezcla entre blancos y negras, al igual que habían mostrado serias reservas frente a otras posibilidades de cruces interétnicos. En ese sentido, las leyes españolas habían ya dispuesto desde muy temprano la recomendación de que los negros solo debían casarse con los de su misma condición (Konetzke, 1958, p. 100).

De allí que los amoríos que se urdieron entre exponentes de esas dos razas fueron dados en el contexto de la ilegitimidad mediante relaciones de hecho, por lo general ocultas y que, a la postre, se convertirían en fuente provocadora de conflictos y rivalidades.

En muchas partes del Nuevo Reino de Granada se alcanzaron a conocer casos de amores extralegales, amancebamientos, concubinatos, pleitos por celos y los consecuentes enfrentamientos por la súbita aparición de hijos producto de esos amores "prohibidos" (Pita, 2015, pp. 87-105). Estas relaciones fueron objeto de especial escándalo y estigmatización, en las que no faltaron los chismes, los odios, las amenazas y toda serie de pasiones humanas.

Durante los primeros años del dominio colonial fueron más fuertes los señalamientos y reacciones de la justicia que ponían presos a los amancebados. Para finales del período colonial, había avanzado tanto la mezcla interétnica que paulatinamente se fueron suavizando las normas segregacionistas y de repudio por esas uniones intercastales. Es, quizás, por ello que para el siglo XVIII la atención se centró no tanto en la represión oficial por esos vínculos "desiguales" sino en los largos y complicados litigios por reivindicar la libertad de la esposa amante y de los hijos.

En el marco de las relaciones amorosas entre amos y esclavas ocurridas en el Nuevo Reino de Granada durante el período de dominio hispánico, el presente artículo tiene por objeto analizar la problemática que giró en torno a la incesante lucha de estas mujeres en lograr que se les concediera el beneficio de libertad, tanto para ellas como para los descendientes de esas uniones amorosas. Este trabajo se inscribe dentro de la corriente de la historia social y de los estudios de grupos subalternos (Arboleda, 2006). Para su realización, se recurrió principalmente a la consulta de fuentes documentales de archivo, así como algunas fuentes bibliográficas que ayudaron complementar el análisis. 


\section{Los caminos de la libertad}

Conceptualmente, la manumisión consistía en un acto jurídico mediante el cual el amo renunciaba voluntariamente a su condición de propietario, al tiempo que el esclavo encontraba la senda abierta hacia su independencia ${ }^{3}$. El proceso se hacía efectivo por medio de un documento oficial denominado carta de libertad, papel que se refrendaba ante las autoridades locales y en el que ocasionalmente el amo especificaba las razones que lo motivaban a tomar tal decisión.

Progresivamente, la manumisión fue adquiriendo un auge inusitado. Para las postreras décadas del régimen de dominio hispánico los amos habían empezado a preferir la mano de obra asalariada por cuanto la adquisición y sostenimiento de los esclavos se había tornado supremamente gravosa. Esto, junto al preocupante incremento de las insubordinaciones, fueron realidades que persuadieron a varios propietarios a prescindir de sus esclavos, y un camino para ello era justamente a través de la liberación.

En la práctica, se utilizaron dos tipos de manumisión: gratuita y pagada. La primera de estas modalidades, también conocida como espontánea, la hacía efectiva el amo en forma deliberada como compensación al servicio y lealtad de sus esclavos, como muestra de afecto fraternal o también con el propósito de favorecer a esclavas con quienes se habían llegado a entablar vínculos sentimentales. Por lo general, la mayoría de estas manumisiones quedaban establecidas mediante disposición testamentaria del amo y por cartas de libertad dadas en vida por él. En esta clase de concesiones tuvo mucha injerencia la cercanía y la resultante consolidación de lazos afectivos.

Hubo situaciones en las cuales no se especificaba la razón por la cual se decidía la liberación y esta discreción podía virtualmente responder al interés de evitar que se ventilaran amoríos subrepticios con esclavas y los posibles frutos de estos escarceos. El gobernador de la provincia de Girón, don Bernabé de la Nava, adjudicó en 1746 carta de libertad a su mulatica Ignacia de tan solo dos años, hija de otra esclava suya llamada Josefa: "[...] mediante a que es descargo de mi conciencia y de la dicha mi esposa por motivos y causas que a ambos nos urgen, los que no podemos expresar y nos es lícito el silenciar [...]" (CDIHR-UIS, Archivo Notarial de Girón, t. 7, ff. 189v-190r).

Para el goce de la libertad no bastaba con que el desprendido amo expresara su convicción de otorgarla. Era indispensable que esa voluntad quedara consignada indeleblemente en un documento escrito, ya fuera en la carta de libertad o en el testamento.

\footnotetext{
La práctica de la manumisión no era nueva puesto que había sido reconocida por el derecho romano y acogida posteriormente por la doctrina cristiana (Klein, 1986, p. 139).
} 
De esta forma, cuando la promesa de libertad fue tan solo una oferta verbal y el amo moría ab intestato ${ }^{4}$, era demasiado complicado comprobar si era válida o era mero embeleco del esclavo. A veces, ni siquiera se hallaban los testigos suficientes que, según la ley, debían ser al menos cinco y de afamada probidad y distinción (Gutiérrez y Pineda, 1999, t. II, p. 240).

Desgraciadamente para los esclavos, no todas las manumisiones eran de aplicación inmediata. A pesar de las elocuentes expresiones de gratitud, lealtad y afecto, una buena cantidad de las liberaciones quedaban supeditadas a ciertos compromisos que dilataban en el tiempo su verdadero disfrute. Esto reflejaba en el amo una posición ambigua mientras que para el esclavo era una incertidumbre que debía sobrellevar con singular estoicismo. Se creó entonces una confusión ya que aun cuando se adquiría legalmente el estatus de libre, se continuaba viviendo bajo las presiones propias del régimen de esclavitud. De todos los condicionamientos, sin duda, el más común era aquel que sometía al esclavo a seguir atendiendo a su amo hasta el momento de su muerte. Desde luego, aquí la intención de fondo era asegurar el servicio hasta los últimos instantes.

Particularmente, en las problemáticas en torno a los ofrecimientos de libertad a la esclava concubina y a los mulatos frutos de esas relaciones, se pudieron presentar al menos tres distintas situaciones. En la primera de ellas el amo se negaba a reconocer su progenitura y de igual modo haber prometido la libertad de la madre y de los hijos. En el segundo escenario, el amo solo expresaba verbalmente su decisión de liberar, pero no quedaba constancia en escritura pública ni en la testamentaria y, por lo tanto, abría campo a los descendientes para negar esas pretensiones de libertad. $Y$, finalmente, la tercera circunstancia en que existía la voluntad testamentaria del amo, pero sus descendientes legítimos recurrían a toda suerte de artimañas con tal de quitarle validez a esa decisión, la mayoría de los casos con el pretexto de la necesidad imperiosa de responder por las múltiples deudas dejadas por el difunto. Para ello, estos deudos no dudaron en poner en tela de juicio la conducta de las esclavas ni tampoco escatimaron esfuerzos para desplegar todo el poder de influencia al nivel local.

Por lo general, este tipo de sumarias eran prolongadas, intrincadas y algunas de desconocido desenlace. No siempre se observó en los dictámenes judiciales uniformidad de criterios, pues existieron diferentes interpretaciones de las normas y de los conceptos emitidos por los juristas especialistas en la materia.

\section{La libertad alcanzada}

Para las amantes esclavas fue arduo el proceso que emprendieron para el reconocimiento de su libertad y de la de sus hijos. Algunas alcanzaron con éxito su

4 Esta condición jurídica ocurría cuando la persona fallecía sin dejar formalizado su testamento. 
cometido gracias a las continuas evidencias y testimonios presentados. Pero, vale precisar que la dicha de estas esclavas involucradas sentimentalmente con hombres blancos no era siempre completa, particularmente cuando lograban reconocimientos parciales de libertad, es decir, decisiones judiciales que beneficiaban solo a ellas o, en otros casos, únicamente a sus hijos, situaciones que llegaron a generar fisuras en la unidad familiar.

Hacia 1797, don Vicente Tamayo, vecino de la parroquia de San Jerónimo en la provincia de Antioquia, fue acusado de estar enredado sentimentalmente con la esclava Carmela de propiedad del presbítero Francisco Díaz. Fruto de esa unión fueron los mulatos Martina, Fulgencia, Josef Claudio y Juan Pablo a quienes Tamayo no solo reconoció sino que también los había comprado para tenerlos a su lado.

Sin embargo, al poco tiempo el mismo Tamayo, agobiado por su crítica situación económica procedió en enero de 1789, a hipotecar sus esclavos y otros bienes con el fin de responder a una deuda pendiente con el regidor don Juan Pablo Pérez de Rublas, de 2000 castellanos de oro en polvo. Persuadido por algunos amigos que le aconsejaron que los padres no podían ser dueños de sus hijos, ni venderlos ni hipotecarlos, al poco tiempo Tamayo firmó un documento en el que declaraba libres a sus cuatro hijos mulatos. Tras el deceso de Tamayo, estos jóvenes acudieron en 1802 ante las autoridades con el fin de hacer efectiva esta promesa ante la oposición de "varios tinterillos con textos legales rabulescos".

Todos los testigos coincidían en que Tamayo había otorgado el respectivo documento de libertad y que durante su vida había reconocido a los citados jóvenes mulatos como hijos suyos. Por tanto, la manumisión otorgada por este vecino no podía perjudicar la hipoteca que recaía sobre sus bienes. Con el fin de saldar las deudas pendientes sin afectar los "sentimientos de humanidad", los deudos de este amo habían propuesto disponer de sus otros bienes: una casa cubierta de iraca, unas tierras, un cultivo de caña de azúcar y veinte mulas.

Al ser confirmada por la Real Audiencia la libertad de los mulatos, Pérez de Rublas interpuso recurso de apelación tras sentir lesionados sus intereses alegando que la supuesta libertad de los cuatro mulatos referidos no era más que una estratagema de los deudos de Tamayo para incumplir las obligaciones contraídas figurando ser sus hijos los que en realidad eran sus esclavos. Esto se ratificaba por el hecho de que Tamayo era casado con una de las señoras principales de la ciudad.

Según algunas voces, los esclavos no podían ser ipso jure libres por haberlos tenido don Vicente en esclavas suyas. Se trajo a colación al célebre jurista Juan de Paz quien había conceptuado que el hecho de estar un amo amancebado 
con su esclava no era motivo suficiente para que esta y los descendientes de esa unión fuesen libres, para lo cual era necesario que ambos se casaran. El hecho de ser su concubina no la hacía igual a él. Se argumentaba, asimismo, que ningún amo tenía la facultad de liberar a sus esclavos:

La esclava que se entrega a su amo no debe ser amparada en libertad, porque de su iniquidad no debe reportar ningún provecho, y porque sería dar anza a todas ellas a que provocasen a sus señores a semejante torpeza para ganar con su cuerpo la libertad, aunque por otra parte se debe castigar a un hombre que se prostituye con su sierva; pero corre muy diferente razón para con los hijos. Estos son inocentes y no son participantes del delito de sus padres. Los hijos son acreedores a todos los derechos de sus padres, y estos están obligados a alimentarlos. No encuentro disposición legal en contrario que castigue a los infelices hijos nacidos de sus propias esclavas (AGN, Negros y Esclavos de Antioquia, t. 6, leg. 6, f. 685r).

Por lo tanto, solo debía declararse libres a los hijos, mas no a las madres. Se decidió entonces respetar la voluntad de Tamayo de manumitir a sus pequeños mulatos. Se hizo énfasis en el hecho de que este hombre no había podido registrar su caso ante los notarios por ser hombre del campo y por no entender mucho sobre la materia. Lo que sí se dejó en claro en esta ocasión es que los hijos mulatos no podían ser acreedores de los derechos de sus padres porque esta regla solo debía tener lugar en el caso de los hijos legítimos.

Hacia 1815 la mulata María Ignacia Duque, residente en la ciudad de Rionegro, viajó hasta Santa Fe de Antioquia, capital de la provincia, para exigir su libertad por haberla reconocido su amo don Manuel Duque como hija natural. Este propietario murió ab instestato y, por lo tanto, no dejó registro escrito de su voluntad.

La mulata y su madre Teodora pasaron entonces a la casa del hermano de su amo, don Juan de Dios Duque, quien las mantuvo en esclavitud con el argumento de que Teodora le había correspondido por herencia paterna. Este hombre se había quedado con la mayoría de los caudales de su hermano: tierras, 20 reses, plata labrada y algún dinero.

Juan de Dios se proclamó como amo de la mulata y se negó a rendir testimonio con el pretexto de pertenecer a la jurisdicción de Rionegro, distinta a la que se estaba adelantando la sumaria. El juez encargado del caso se excusó de no haber practicado algunas indagatorias debido a las múltiples ocupaciones de su despacho en asuntos de gobierno, pues se encontraba encargado como Sub-Presidente del cantón capitular, mientras que el escribano había estado también muy ocupado en procesos de ventas y remates.

Algunos testimonios como el de Enrique de Villa daban cuenta de haber oído decir que la dicha María Ignacia no era hija de don Manuel y que el trato que 
este le daba era igual al de otros domésticos. Pero una tesis bien distinta era la que se desprendía del testimonio rendido por el ciudadano Pedro Campero, administrador del ramo de aguardientes, quien certificó

[...] que en el tiempo que permanecía asociado con don Manuel Duque, observé que este daba un trato afectuoso a María Ignacia Duque, y que la María Ignacia no le trataba de amo sino de padrino, y a la madre de Duque de mamá, de que un día le traté de comprarla y me contestó que no se vendía [...] que Duque no llegó a decirme fuese su hija, pero supongo que sería por vergüenza o respeto, pues Juan de Dios Duque y su mujer eran sabedores que la nominada María Ignacia es hija del difunto Duque (AHA, Negros y Esclavos, t. 25, leg. 37, f. 401v).

Hacia 1818 se levantaron nuevos testimonios que corroboraron estas últimas aseveraciones, lo cual convenció al procurador Fernando Uruburu de que eran pruebas más que suficientes para concluir que María Ignacia era hija de don Manuel Duque, lo cual hacía "indisputable" el derecho que esta mujer tenía no solo a la libertad sino al quinto de los bienes de su finado señor, para lo cual había que nombrar un curador y tutor que se encargara de administrar este patrimonio.

Se comprobó que era totalmente falso el argumento esgrimido por Juan de Dios, quien aseguraba que la madre de María Ignacia le pertenecía. En realidad, esta mulata había vivido siempre al lado de su padre y en ningún momento el hermano de este había alegado derecho de propiedad sobre ella y sobre su madre esclava.

\section{Los amos se retractan}

Una actitud común en los amos fue la de arrepentirse o negar libertades ofrecidas inicialmente a sus amantes esclavas y a los hijos de estas uniones. Estos súbitos cambios de opinión pudieron tener su origen en la presión social y en la oposición que experimentaron estos propietarios por haberse involucrado sentimentalmente con una mujer considerada de baja esfera social.

Francisco Freire, un portugués asentado en la ciudad de Tunja a principios del siglo XVII, adquirió una esclava llamada Magdalena y durante largos años mantuvo "cópula carnal" con ella, resultado de lo cual fueron tres hijos: Isabel, Juan Pérez y Juan Barbosa. Durante el tiempo de estos devaneos, el portugués trató con esmerado amor a su esclava, considerándola como persona libre y otorgándole carta de manumisión, pero con la condición explícita de que tanto ella como sus hijos le sirvieran hasta el final de sus días, tal como quedó oficialmente estipulado en escritura pública.

Sin embargo, al cabo de un tiempo, Freire desconoció tajantemente los beneficios conferidos y optó por firmar un documento mediante el cual ordenaba 
entregar la negra y sus vástagos a don Sancho Girón, gobernador y capitán del Nuevo Reino, quien los mantuvo sometidos a prisión y a inclementes castigos. Por estas anómalas circunstancias, Magdalena debió acudir en 1632 ante la Real Audiencia en busca de amparo. Ella argumentaba el legítimo derecho que tenía de gozar la vida en estado de libertad conforme al documento suscrito por su señor y teniendo, además, como sustento probatorio lo ampliamente conocida que era en la ciudad su estrecha amistad con el portugués.

Pidió, eso sí que, mientras se resolvía su situación jurídica, ella y sus hijos no fueran devueltos a su antiguo propietario por las eventuales represalias y maltratos que este pudiese aplicar por haberse presentado en su contra una denuncia ante la justicia.

El cuestionado amo había entregado 100 pesos a Magdalena para que ella "cuadrase" matrimonio con un mulato de la ciudad llamado Sebastián, con el fin de que este hombre pudiese comprar la libertad de su prometida. Era esta una estrategia muy habitual en los propietarios con miras a borrar ante la sociedad la relación que por varios años habían mantenido con sus negras.

Freire aducía que algunos enemigos suyos se habían confabulado con Magdalena para arruinarlo económicamente y para que ella lo envenenara. Aseguraba, además, que Juan Pérez no era hijo suyo, sino de un soldado que había fallecido en la Guayana. Pero estas aseveraciones fueron contradichas por otros testimonios, según los cuales, un día cuando iba Freire en compañía de unos amigos para la ciudad de Tunja se encontró en el camino al referido Juan Pérez, quien se disgustó por haberlo tratado su padre como esclavo y no como hijo. El joven se había escapado de la casa a los doce años de edad y trabajaba por su propia cuenta con el transporte de unas mulas. Freire exigió a las autoridades "poner perpetuo silencio" a este mulato para que dejara de decir que era hombre libre y descendiente suyo (AGN, Negros y Esclavos de Boyacá, t. 2, f. 356r).

En noviembre de 1796 desde la villa de Guaduas, la mulata Lucía Viana denunció ante el gobernador de Mariquita a su amo don Antonio Burgueño por haber disfrutado el "claustro virginal" a cambio de ofrecerle la libertad a ella y a su hijo Sebastián, un beneficio que dos décadas después aún no se había hecho efectivo. El joven Sebastián también recordó a los jueces que en el terremoto ocurrido el día 16 de junio de 1806, fue él quien rescató a su padre sepultado entre las ruinas, un motivo más que lo convenció de tener ganada la gracia de ser libre. Según la tradición, cuando un esclavo cumplía un acto heroico en defensa de su amo, merecía quedar en libertad (Gutiérrez y Pineda, 1999, t. II, p. 193).

Pocos meses después este joven acudió ante la justicia reclamando el derecho a la libertad y solicitando, además, ayuda, pues su amo lo había castigado y 
enviado a la cárcel al enterarse que había viajado hasta la villa de Honda a tratar sobre esta denuncia. Un verdadero drama había sufrido Lucía, pues había sido vendida en la ciudad de Remedios en donde finalmente falleció. El gobernador no había podido adelantar las diligencias de rigor, pues no contó con la ayuda de las autoridades de Guaduas (AGN, Negros y Esclavos de Panamá, t. 4, f. 450r).

Para el acusado estos no eran más que señalamientos infundados nacidos de la mala voluntad de la mulata Lucía, pues atribuía todo a sus "intrigas y astucias", además de que en términos jurídicos creía que no podía prestársele mucha atención al simple testimonio de una esclava. El joven Sebastián lanzó agudas críticas contra el proceso por estar empañado de vicios procedimentales y nulidades, y por la inoperancia de los funcionarios que mantenían cierta cercanía y amistad con el amo implicado.

El mulato criticó, además, el accionar del gobernador don Juan Pérez Montes quien, como juez conocedor de la causa, había comisionado para ello al alcalde de segundo voto, con lo cual se vio dilatado el proceso. También tenía serias sospechas sobre la conducta de los procuradores que habían intervenido en el juicio pues ninguno de ellos, excepto don Agustín Mendivil, había cumplido con su misión por querer complacer a don Antonio. Del alcalde ordinario de primera nominación tampoco había recibido atención a su demanda, mientras que el otro alcalde ordinario se había ausentado, aparentemente por enfermedad. Un mal concepto se tenía también del anterior escribano de la villa don Luis Barrera por querer beneficiar y proteger al señor Burgueño, pues se negaba a recoger las declaraciones de los testigos presentados por el demandante.

Meses más tarde, desde la cárcel de Honda, el mulato propuso a la justicia que se recibiera el siguiente testimonio de su padrino Pedro José Pérez, en el cual se hace una referencia explícita al parecido fenotípico entre padre e hijo y al reconocimiento popular de ese vínculo filial:

Querido ahijado: para mi descargo de mi conciencia y contestación de tu anterior declaro lo siguiente. Primeramente que mi compadre me habló para que fuera tu padrino y desde aquel tiempo me ha reputado y mirado como compadre y así nos hallamos que mi comadre Lucía tu madre me confesó eras hijo del dicho compadre Burgueño a que se agrega que, el que te vea, no dirá otra cosa por lo muy parecido que sois a él. Que es notorio todo lo expuesto por cuyo motivo los más vecinos de esta villa te miran por hijo de mi expresado compadre y no esclavo como lo pretenden (AGN, Negros y Esclavos del Tolima, t. 3, f. 700v).

Igual de contundente fue el testimonio brindado por don Félix Espinosa y Carrera:

[...] a más que hace veinte y tantos años que tu madre le comunicó a la mía eras hijo del maestro Burgueño, notoriamente lo he oído decir en esta villa; pero lo que me 
hace creer que sois hijo del expresado Antonio Burgueño, es porque te pareces tanto a este, en términos que no sé cómo lo niega tu padre (AGN, Negros y Esclavos del Tolima, t. 3, f. 701r).

Al llegar este caso a manos del virrey Antonio Amar y Borbón, de inmediato ordenó que el alcalde ordinario de primero voto llevara a cabo el juicio y se obligara al procurador a que cumpliera con su deber de defender la causa de sus protegidos. El proceso pasó luego a la oficina del abogado don Antonio Viana, quien se pronunció a favor del amo.

En razón a esta sarta de impasses, el joven Sebastián acudió a la Real Audiencia para que, en calidad de representante legítimo del poder del Monarca, se administrara justicia en este caso y cesaran los atropellos contra él. Otras fallas procedimentales fueron denunciadas por el joven mulato como el hecho de que algunos testigos habían declarado sin el previo juramento, además de que se había recibido el testimonio de un menor de edad.

Complicaciones mayores sobrevenían cuando el amo reversaba su decisión de liberar a un esclavo inmiscuido en triángulos amorosos. Hacia 1800 compareció ante los juzgados de la ciudad de Girón el esclavo Gregorio exponiendo que su amo don Manuel Mantilla y Salas, quien por ese entonces fungía como alcalde de Piedecuesta, le había propuesto que si se casaba con la mulata libre María Sánchez abrazaría en menos de seis meses el aliciente de la libertad.

El móvil que alentaba a este vecino a lanzar tan peculiar propuesta era para ocultar sus amoríos con esta mujer a la cual tenía trabajando como sirvienta en su casa de estancia. El pacto contemplaba, además, que el esclavo debía fingir ser el legítimo padre de una hija que había resultado de la ilícita relación con el ofrecimiento de apoyo económico para el sostenimiento de esta improvisada familia. Pese a las insistentes pretensiones de Gregorio para que se le manumitiera inmediatamente, al final accedió a las condiciones expuestas y terminó casándose.

Mantilla había impedido a la madre de la hilandera María llevársela bien lejos y estando ya a punto de dar a luz fue enviada intencionalmente a la villa de San Gil de donde se devolvió a su ciudad de origen noventa días después del parto. Luego le propuso sacar a la recién nacida para que la criaran en otro lado, pero la mulata se rehusó. Nótese aquí cómo la actitud del vecino se batía entre el interés por evitar el señalamiento público que significaba una relación desigual de este tipo y la precaución de no apartarse tanto de su subrepticia familia.

Luego de diez meses, el amo se negó tajantemente a cumplir la parte que le correspondía en el trato con el sofisma de que solo autorizaría la manumisión hasta después de sus días. Este inesperado viraje incitó al mulato a traer cuatro testigos que presenciaron el momento en que se hizo el convenio. 
Una vez recluida en la cárcel acusada de amancebamiento, María confesó haber vivido donde Mantilla a quien definió como su "compadre espiritual", y reconoció que cuando estuvo casada con el esclavo, la mantenía no este sino aquel. Gregorio, por su parte, se quejó de que su señor lo oprimía reduciéndolo a prisión con collar en el cuello para que no se escapara y con la obstinada intención de enviarlo a Sogamoso en calidad de concertado.

El procurador Miguel Reyes, protector del esclavo, instó a las máximas instancias de justicia acogerlo en su petición y exigir al propietario que fuera consecuente con su propia palabra:

[...] Mantilla debe ser vigorosamente compelido a la compensación que estipuló con su siervo, sin que se diga que por serlo estaba este sujeto a ejecutar la voluntad de su señor, sin quedar este obligado al premio prometido por su obediencia, pues moralmente hablando ni los esclavos ni los hijos de familia pueden ser compelidos por sus amos o padres contra su voluntad y en el presente caso (como antes dije) faltando a la condición sobre que rodaron las esponsales no solo resulta perjuicio y agravio contra el esclavo sino también contra la consorte que se casó bajo la confianza cierta de la libertad de su marido (CDIHR-UIS, Archivo Judicial de Girón, caja 36, f. 509v).

Sin embargo, el propietario desestimó los cargos y catalogó todo esto como producto de una persecución y complot en su contra.

\section{La oposición de la familia legítima}

Como también lo demuestran varias historias, la familia del pretendiente blanco fue muy obstinada en su empeño por tratar de omitir o perturbar el derecho de libertad adquirido por la esclava amante y sus hijos; todo esto, debido a que veían menoscabados sus intereses por la vía de la herencia.

No hay que perder de vista el hecho de que el valor de los esclavos llegó a representar un capital apreciable dentro del cúmulo de pertenencias, incluso alcanzando a tener mayor peso dentro del total del patrimonio, como fue el caso de algunos hacendados y propietarios de minas. En términos generales, el precio promedio de un solo esclavo adulto ${ }^{5}$ pudo superar al de una modesta casa o un pedazo de tierra (Pita, 2015a, p. 287). En otros casos, existía cierta resistencia a prescindir del trabajo del elemento esclavo cuando este personal de servicio era la única fórmula de sustento para sus amos. Este par de circunstancias ayudan de alguna manera a entender el empecinamiento de la familia del hombre blanco en dilatar o impedir cualquier aspiración de libertad por parte de la esclava envuelta en amoríos furtivos.

\footnotetext{
$5 \quad$ El valor aproximado de un esclavo adulto en el Nuevo Reino de Granada oscilaba por lo general entre $200 \mathrm{y}$ 300 pesos.
} 
Uno de los casos que muestra esta situación fue protagonizado por el capitán Antonio de Herrera Lucero en la ciudad de Ocaña quien, habiéndose casado con su esclava, la había declarado libre a ella y a los frutos de esta unión, tal como quedó estipulado en su testamento firmado el 7 de diciembre de 1689:

[...] declaro para el descargo de mi conciencia que muchos años después del fallecimiento de la dicha doña Gertrudis Abad mi esposa, estando libre del dicho matrimonio y hábil para poder contraer otro en una negra criolla mi esclava que fue y hoy es libre, nombrada Florinda, hube por mis hijos a Antonio, Dominga, Juan, Matías y Pascuala, declárolos por tales mis hijos y es mi voluntad que gocen de su libertad (AGN, Negros y Esclavos de Santander, t. 5, f. 449v).

Al año siguiente, el capitán Herrera decidió entregar su hijo Matías a su yerno para que lo acompañara, a cambio de lo cual este se comprometía a educarlo, adoctrinarlo y respetarle su condición de libre.

Sin embargo, hacia 1692, el mulato Antonio, habiendo adquirido su mayoría de edad y en representación de sus otros cuatro hermanos, debió recurrir a las autoridades para que se hiciera efectivo el citado testamento a través del cual se les reconocía como hijos naturales y personas libres, declaración que había sido refrendada por uno de los alcaldes de la ciudad, pero desconocida por el otro alcalde don Lucas Varas de Valdés, quien, de manera arbitraria, procedió a venderlos como esclavos tras afirmar que el difunto capitán Herrera debía una apreciable cantidad de dinero por concepto de la dote de una de sus hijas. Este cuestionado funcionario era esposo de doña Luisa de Herrera Abad, hija legítima del primer matrimonio del capitán Herrera, circunstancia por la cual los mulatos permanecieron arbitrariamente en estado de esclavitud durante tres años.

El argumento central de los mulatos afectados era que, aún si fueran esclavos, había otros bienes herenciales que podían utilizarse para el propósito de saldar las deudas pendientes de su difunto progenitor, sin necesidad de vulnerarles el derecho de gozar de una vida libre de ataduras.

Finalmente, por decisión de la Real Audiencia, se decidió amparar la libertad conferida a los mulatos, y quienes se atrevieran a desconocer este fallo recibirían a manera de castigo 200 patacones de multa, si eran blancos españoles y 200 azotes, si eran mestizos o negros.

Escolástica Rudesinda había protagonizado por largo tiempo un romance con su amo Jerónimo Ramón domiciliado en la villa de Cúcuta. Dos hijos fueron finalmente el producto de esos tórridos escarceos. Posteriormente la mujer se casó con un mulato libre bajo la anuencia de su propio señor, siguiendo la táctica utilizada en aquel entonces por el amo blanco para tratar de contener el descrédito público que implicaba el entrometerse sentimentalmente con una esclava. 
Testigos dieron fe de que Ramón le tenía expedida a Escolástica carta de libertad, beneficio que solo se haría efectivo hasta el fallecimiento de él. Sin embargo, en 1807 al momento de ocurrir su deceso, sus herederos legítimos, es decir, su esposa y sus hijos blancos desconocieron rotundamente el derecho que les asistía a la mulata y a algunos de sus hijos bajo la argucia de que era un otorgamiento ilegal, así como lo había sido también la relación amorosa. Veamos las palabras pronunciadas por el albacea don José Gabriel Peña:

No presentan al juzgado sino un montón de contradicciones y falsas imputaciones, calumnias y mentiras que en caso de surtir algún efecto debía ser el de que la citada Escolástica Rudesinda fuese restituida al estado de esclavitud por la notoria infidelidad e ingratitud de manchar el buen nombre, fama y reputación que conservó su amo hasta la muerte (AGN, Negros y Esclavos de Santander, t. 5, f. 248r).

Nótese en este pronunciamiento cómo se le endilga toda la tacha a la amancebada esclava como portadora del pecado y causante de la deshonra del hombre blanco. El caso fue remitido para estudio de don Miguel Valenzuela y don Eugenio García, abogados de la Real Audiencia residentes en la ciudad de Girón, quienes confirmaron que efectivamente la libertad había sido procedente y tenía plena vigencia.

No obstante este fallo, los hermanos Miguel, Felipa y María Inés, hijos legítimos del extinto Ramón, pusieron en duda la libertad de los mulatos engendrados antes de que se le concediera a la madre este mismo beneficio, inquietud que fue avalada y respaldada por el par de abogados designados. En virtud a este dictamen, se resolvió cotejar las partidas de bautismo de todos los hijos de Escolástica con la fecha en que se suscribió el indulto de libertad para saber a ciencia cierta a quiénes les comprendía el citado favorecimiento y a quiénes no.

Se concluyó entonces que la mulata María Petronila, hija de su amo, y los mulatos Rosa, Toribio y Francisco Apolinar, descendientes del mulato libre, quedaban cobijados por la declaratoria de libertad. Debido a que algunos de estos jóvenes estaban en poder de los herederos de Ramón y otros bajo la potestad de particulares, se les apremió a estos propietarios para que los devolvieran a su progenitora y reconocieran el derecho refrendado. Entre tanto, José Trinidad, otro de los hijos del amo, quedó excluido del beneficio de libertad por haber nacido cuando la madre aún era esclava y, de inmediato, se notificó este dictamen a su amo don Domingo Peralta.

La animadversión hacia los derechos de los hijos habidos con esclavas llegó a tal punto que se buscó incluso la forma de desconocer la compra de libertad. En la villa del Socorro en 1797, se dio el caso de don Gregorio Roldán quien se vio involucrado con una esclava suya de cuyo romance nació Domingo Roldán, el cual en calidad de hijo natural vivió bajo el mismo techo paterno. Con el 
transcurrir del tiempo, el menor se ganó el resentimiento de la esposa de su amo, doña Petronila Uribe.

Pese a que Domingo había comprado su libertad, doña Petronila intentaba reducirlo a esclavitud "por frívolos pretextos y particulares sentimientos", pues había intentado anular la respectiva carta de libertad bajo el argumento de que el mulato no había pagado el dinero correspondiente a su verdadero valor. No obstante, esta tesis tenía muy poco asidero, por lo que se deduce que el odio hacia él se atribuía en realidad a que era hijo natural de su difunto esposo. Aducía doña Petronila que el oficio de sastre que ejercía el mulato le confería un valor mayor del que había pagado por su libertad, un argumento que fue desvirtuado por la defensa, pues el oficio lo había aprendido cuando ya era libre y vivía en la ciudad de Santa Fe. Tras aducir que el joven mulato había actuado de mala fe, doña Petronila logró con su poder de influencia en el nivel local que lo apresaran, lo pusieran en el cepo y le embargaran sus cortas pertenencias.

Pese a las advertencias lanzadas por el procurador en el sentido de que doña Petronila mantenía una fuerte influencia en las autoridades y funcionarios locales, el fiscal Mariano Blaya ordenó devolver el caso al alcalde ordinario de la villa para que impartiera justicia sin "molestar" a Domingo, ante lo cual el procurador insistió nuevamente en que el proceso pasara a revisión de los tribunales de Santa Fe: "[...] con el intento de excusarlo [al esclavo] de las opresiones a que va expuesto y prudentemente se teme de aquellas parciales justicias y del poder y valimiento de la que fue su señora" (AGN, Negros y Esclavos de Antioquia, t. 1, f. 447r).

Al verse el liberto sin amparo en aquella villa del nororiente neogranadino, emprendió un largo viaje hasta la capital para implorar protección de la Real Audiencia. Finalmente, este máximo tribunal accedió a revisar directamente el expediente para lo cual ordenó como medida temporal que Domingo saliera de la prisión por no haber un motivo probado de gravedad que justificara en ese momento mantenerlo bajo rejas.

\section{Resentimientos y rivalidades entre hermanos}

Desde luego, tampoco era extraño descubrir en esta enmarañada urdimbre de pasiones la manifestación de ciertas rivalidades entre los hijos naturales y los hijos legítimos. En ocasiones, estos últimos no escatimaron esfuerzos en defender pertinazmente el ser blancos descendientes de matrimonio legalmente constituido por dos similares étnicos, condición que los convencía plenamente de su superioridad social y disfrute de mayores prerrogativas en comparación con aquellos hermanos "teñidos" con la sangre de los esclavos. 
Así aconteció a principios del siglo XVIII en inmediaciones de la ciudad de Vélez con los pardos libres Francisco y Benito, hijos naturales del capitán Manuel de Herrera Sotomayor. Ellos debieron soportar una andanada de ataques y cizañas provocadas por su hermano don Juan Herrera y Tovar. A juzgar por los términos de la denuncia elevada por este hijo legítimo del capitán, aquel par de hermanos de color se habían valido de la confianza brindada en el hogar paterno para sacar información sobre la localización exacta de un cofre repleto de dinero que supuestamente había enterrado el viejo poco tiempo antes de fallecer. Para sustentar aún más su acusación, Juan Manuel se apoyó en el testimonio de varios lugareños que dieron fe del ilícito cometido y del derroche de ese tesoro avaluado en 10.000 pesos, sindicando, además, a Benito de practicar malas costumbres hasta el punto de haberse atrevido a hurtarle 300 pesos a su padre.

Confinados en prisión y con sus cortas pertenencias embargadas, los dos procesados clamaron pronta justicia tras alegar que todas estas calumnias y maquinaciones eran resultado del rencor que desde vieja data les guardaba su propio hermano: "[...] siempre tirando a oscurecernos el derecho que nos compete como hijos naturales del dicho capitán don Manuel de Herrera" (AGN, Real Hacienda, t. 59, f. 663v). Según ellos, Juan Manuel aprovechó el hecho de que su tío era alcalde ordinario de la ciudad para enviarlos al cepo y aplicarles con máximo rigor otra serie de castigos.

El sargento mayor don Tomás de Rojas Revollar mantuvo en la ciudad de Tunja íntimos vínculos con la mulata esclava Gertrudis Rita de Alvarado de propiedad de su esposa doña Francisca Javiera López Garrido. Fruto de esos amoríos fue un mulato al que bautizaron con el nombre de Francisco Javier a quien don Tomás reconoció como hijo, declarándolo libre a él y a la mulata para transitar por todas partes, para lo cual se expidió la correspondiente escritura. Durante cuatro años este joven anduvo por varios parajes de la provincia sin ser requerido ni molestado por nadie.

Al momento de fallecer don Tomás, sus hijos legítimos don Ignacio y don Pedro de Rojas Garrido se presentaron ante las autoridades negando que el mulato fuera hijo de su padre y pretendiendo que él y su madre mulata volvieran al estado de esclavitud, para lo cual intentaron venderlos.

Estos hermanos ocupaban empleos importantes en la ciudad, pues don Pedro era depositario general y regidor capitular. Para probar la acusación hecha, ellos pusieron en duda la reputación de la mulata arguyendo que había sido sorprendida en concubinato con Santiago Izaguirre y que, además de esto, el verdadero padre del joven Francisco Javier era Lorenzo de Bustamante, quien había trabajado como amanuense del sargento mayor y vivido una larga temporada en su casa. Según aseveró el par de hermanos, Bustamante había reconocido al mulato como 
hijo suyo, quien andaba durante varios años en calidad de fugitivo. Se alegaba, asimismo, que el sargento mayor no podía haber otorgado carta de manumisión siendo la mulata perteneciente a los bienes dotales de doña Francisca Javiera y que, aunque fuese legítima la libertad, esta había sido conferida después de dar a luz y, por tanto, el pequeño no era cobijado por dicha concesión. Ambos hermanos clamaron no ser perjudicados en su calidad de auténticos herederos de los bienes patrimoniales de sus progenitores.

Para imprimirle más peso a su defensa, don Ignacio y don Pedro allegaron copia de la cláusula 28 del testamento dejado por doña Francisca Javiera el 25 de enero de 1753, en la cual se estipulaba que, si el mulato fugitivo era hallado, fuera vendido de inmediato y su valor entregado a su hija María Rosalía, quien llevaba vida religiosa en uno de los conventos de la ciudad. Se recordó, además, que don Tomás había muerto ab intestato, por lo cual no pudo dejar cláusula testamentaria otorgando libertad. Se adujo también que no había ningún indicio de que el sargento mayor tratase al mulato como hijo, para lo cual se adjuntaron sendas certificaciones expedidas por el cura de Ramiriquí don Manuel Guarín y el cura del pueblo de Tibaná, en las que se aseguraba que aquel joven era reconocido como esclavo. Se dijo incluso que él había entregado 32 pesos para comprar su libertad, pero esta propuesta le fue negada por cuanto estaba muy por debajo de su valor comercial. El mulato fue finalmente hallado en Santa Fe y puesto en prisión mientras se resolvía su situación.

Ante estos señalamientos de los demandantes, la mulata Gertrudis Rita se esforzó por allegar una serie de pruebas y testimonios reveladores. En el interrogatorio de 10 puntos, los declarantes dieron fe de que, cuando don Tomás de Rojas era corregidor del partido de Tensa, siempre la llevó consigo para que le sirviera como cocinera. Cuando este hombre salía de la jurisdicción a algún otro lugar distante, también lo hacía en compañía de dicha mujer.

Según se dijo, ella era de color "bastantemente blanco" y "[...] su porte y trato en el vestir y demás señales no demostraban fuera criada del dicho don Tomás quien siempre hizo grande estimación de la predicha Gertrudis". Basilio Álvarez, soldado de la compañía de Alabarderos, confesó que don Tomás la trataba prácticamente igual que a su legítima esposa.

Según Ignacio Díaz, otro de los testigos registrados, cuando Francisco Javier era párvulo lo pusieron a leer en la hacienda junto con los demás hijos legítimos de don Tomás, usando para ello el mismo traje "sin diferencia alguna", haciendo énfasis en que ningún otro criado de la casa gozaba de tales privilegios. Años después, cuando don Tomás pasó a la ciudad de Tunja, llevó a sus dos hijos legítimos y a Francisco Javier, y a todos los matriculó en la escuela donde estuvieron por algún tiempo. Luego, cuando fue corregidor de Paipa, nuevamente se 
llevó al mulato a quien trataba "con un modo tan decente y particular que por tal era singularísimo". Por todas estas circunstancias, coincidieron los testigos en sus declaraciones, era ampliamente reconocido que Francisco Javier era hijo de don Tomás. Igualmente, se aseguró que antes de su muerte, este hombre había manumitido a la mulata Gertrudis Rita, sin que en ese momento surgiera alguna objeción por parte de los herederos legítimos.

Aunque en el expediente no figura el epílogo de este caso, estas últimas declaraciones ofrecen indicios muy contundentes que hacen pensar con certeza en la existencia de la conexión filial entre el mulato y el sargento mayor (AGN, Negros y Esclavos de Boyacá, t. 2, ff. 872r-906v).

En otro episodio acaecido en esa misma provincia, don Carlos Álvarez había comprado a mediados del siglo XVIII la esclava Lorenza Vallejo y producto de los amoríos sostenidos con ella fue una hija llamada Josefa. El problema era que Álvarez siempre les decía a Lorenza y a su pequeña que no eran esclavas pero, al momento de estas pedirle el otorgamiento de la respectiva carta de libertad, él se rehusaba alegando que estaba muy ocupado, aplazando con ello indefinidamente esa decisión.

Cuando Josefa alcanzó la mayoría de edad, apareció doña Manuela Álvarez, la hija que tenía su padre con su legítima esposa, aduciendo que Lorenza era esclava suya como parte de la dote que don Carlos le había dejado y por tanto procedió a convenir contrato de venta con don Francisco López, uno de los polvoreros de la ciudad. En razón a estas incidencias y, con la convicción de que las justicias locales no oirían ni atenderían oportunamente su reclamo, Josefa envió en 1769 una carta a las autoridades virreinales asentadas en Santa Fe en busca de amparo a su condición de libre alegando que su padre tenía una casa que podía vender para responder con la dote prometida.

Solicitó, además, que se le otorgara la respectiva carta de libertad, pero sin que debiera pagar ningún derecho por ello en atención a su comprobado estado de pobreza pues había pedido ayuda a los abogados de pobres y ellos se negaron arguyendo que se hallaban sumamente ocupados con causas criminales y que, primero ella tenía que comprobar con testigos su precaria situación económica. En respuesta a estos inconvenientes, la Real Audiencia impartió instrucciones a las justicias de la ciudad de Tunja para que atendieran el caso sin implicarle costo alguno a la peticionaria (AGN, Negros y Esclavos de Boyacá, t. 2, ff. 953r-954v).

Por esa misma época, Juan Francisco de Ibargüen había sostenido en la ciudad de Quibdó amores con su negra esclava, fruto de cuya relación fue un hijo llamado Agustín. Tras la muerte de Juan Francisco, su hermano Juan Bautista conoció al joven Agustín y de inmediato pudo percatarse del parecido en las 
facciones con su padre, motivo por el cual no lo ocupó en los rigurosos oficios de minería sino que lo envió a la ciudad de Ibagué a la casa de su hermana doña María Manuela de Ibargüen, con el fin de que aprendiese a leer y escribir.

El joven pardo no solo adquirió esta destreza sino que les enseñó a sus primos, los hijos de doña María Manuela. En este hogar, fue tratado con estimación y ocupado en los mandados de la casa. Años después, el mismo Juan Bautista, en calidad de albacea de la testamentaria de su hermano, viajó hasta Ibagué con el fin de comprar la libertad de su sobrino Agustín. Sin embargo, al fallecer Juan Bautista se desconoció este otorgamiento de libertad y por consiguiente el pardo fue incluido en sus bienes y dividido entre sus hermanas doña María Manuela y doña Tomasa de Ibargüen.

Por estos motivos, Agustín se presentó en la ciudad de Quibdó en 1780 para elevar la respectiva demanda de reivindicación de su libertad. Luego de haber aportado tres testigos, el joven era consciente de la desventaja que tenía en este proceso judicial por falta de defensor y por el inmenso poder desplegado por la contraparte (AGN, Negros y Esclavos del Cauca, t. 3, f. 840r).

Ante estas dificultades y con miras a que no se dejara de administrar justicia en este asunto, el gobernador decidió trasladar el proceso al virrey y a la Real Audiencia para que se dictara el respectivo fallo. Los oidores ordenaron mantener en libertad al mulato hasta tanto se recopilaban todas las pruebas necesarias.

\section{Estrategias para esquivar libertades}

El pago de deudas pendientes y las donaciones fueron dos de las estrategias utilizadas para dejar sin piso las libertades otorgadas a los hijos de los vínculos amorosos entre un hombre blanco y una esclava. Este tipo de circunstancias terminó involucrando a terceros, lo cual hizo que los litigios se tornaran más complicados y prolongados.

Por considerarse "una pobre mujer esclava e inútil" que carecía de palabras para explicar bien su demanda, María Encarnación, pidió en 1778 a las autoridades de la ciudad de La Plata al sur del Nuevo Reino que le nombrasen defensor para elevar con más fervor la queja contra su amo Juan Manuel Rodríguez para que le entregara la carta de libertad.

En atención a esta petición, fue designado como defensor don Juan Francisco Ramírez Quintero, quien relató cómo hacía diez años aproximadamente que el dicho Rodríguez había comprado esta mulata y al poco tiempo vivía en "ilícita amistad" con ella, prometiéndole libertad a cambio de que le procreara cinco hijos. Según adujo el defensor, esta mujer respondió inocentemente a las 
intenciones de su amo por ser "muy amable" y sin saber que estaba incurriendo en una falta ante los ojos de Dios. Luego de haber mantenido esta relación, él se negó tajantemente a cumplir la promesa.

Según adujo Rodríguez, la justicia no debía atender la demanda de su esclava porque era "injusta y temeraria" y "nacida de ingratitud y mala voluntad". Por este supuesto odio de la esclava, su amo junto con su esposa María Núñez decidieron de común acuerdo donarla para "[...] hacer servicio a Dios nuestro Señor con el valor de la nominada mulata".

Con el fin de oficializar esta decisión, la pareja se presentó ante el cura Joaquín Antonio de Morales y, con la presencia de escribano, dijeron

[...] que por la grande voluntad que han tenido siempre de ayudar con alguna cosa, contribuyéndola de sus bienes para el culto de la Divina Majestad que se haya sacramentado en la santa iglesia parroquial de esta sobredicha ciudad, teniendo como tienen justos motivos para no admitir ni tener en su poder y servicio a la consabida mulata su esclava, y porque además de no tener hijos de su matrimonio que les puedan heredar forzosamente, ni ascendientes legítimos, tienen suficiente caudal para mantenerse ambos [...] en esta atención ambos de mancomún y cada uno in solidum [deciden] otorgar por la presente y en la mejor vía y forma que haya lugar en Derecho, que hacen gracia y donación buena, pura, mera, perfecta e irrevocable, de las que el derecho llama inter vivos de la susodicha mulata María de la Encarnación su esclava a nuestro Señor Sacramentado que se venera colocado en la dicha santa iglesia parroquial de esta expresada ciudad, a favor de su sagrada cofradía (AGN, Negros y Esclavos del Tolima, t. 4, ff. 408r-409r).

Nótese aquí la intención de la esposa traicionada de alejar a la esclava donándola con el fin de evitar su liberación y su eventual cercanía con Rodríguez.

El caso se complicó aún más al precisarse que la esclava estaba también hipotecada por valor de 1000 patacones al señor Luis Rodríguez Durán, procurador y padre general de menores. No obstante, el amo aclaró que para hacer la donación se había contado con el previo consentimiento del procurador.

Así entonces, en este lío jurídico entraron en juego tres partes: el procurador que luchaba por la libertad de la esclava, los amos que insistían en mantenerla en esclavitud y la Iglesia que a través del mayordomo de la cofradía pretendía hacer valer la escritura de donación.

Hábilmente Rodríguez recurrió a una práctica muy común para ocultar su concubinato: casar a su amante, quien formalizó unión con el pardo libre Antonio López. Este matrimonio tenía un doble propósito pues, según la ley de vientres, los cinco hijos quedarían en estado de esclavitud al presumirse que habían sido engendrados en la nueva relación. Rodríguez confesó que había prometido la libertad de su esclava, pero con la condición de que solo se hiciera efectiva hasta después de su fallecimiento. 
Don Sebastián Centeno, mayordomo de la cofradía, exigió que le fuera entregada la esclava, pidiendo, además, descalificar las aspiraciones de libertad de esta mujer por ser ella "maliciosa" y frívola". Además, argumentaba que la demanda de María Encarnación estaba viciada de nulidad, pues ella por sí sola no tenía voz para comparecer en juicio por ser casada y por no contar con el permiso de su esposo y, por consiguiente, la demanda interpuesta no tenía ningún sustento legal. Según se dijo, con sus declaraciones sobre el supuesto concubinato con su amo, la esclava había manchado el honor de su esposo pardo.

Centeno hacía ver cómo en ninguna doctrina jurídica estaba contemplado que una esclava accediera al derecho de libertad por el solo hecho de estar en concubinato con su amo, pues la ley solo otorgaba ese beneficio a aquellas negras que se casaran con sus señores. Consideraba, asimismo que, si a fin de cuentas era cierta la promesa del amo, esta quedaba invalidada por estar enfocada hacia "torpes" propósitos.

Finalmente fue entregada la esclava al mayordomo de la cofradía. El defensor de la mulata, entre tanto, presentó dos testigos, uno de los cuales, Francisco Losano, dio fe de haber escuchado al amo que le había prometido libertad a la esclava hasta cuando le "ajustara" cinco hijos y, en vista de que ya había cumplido a cabalidad ese desafío, la mulata era merecedora de ser libre. A fin de no perjudicar este otorgamiento de libertad ni la donación hecha a la cofradía, el defensor propuso que el amo le pagara a la esclava su justo valor comercial para que ella pudiera automáticamente redimirse de su estado de esclavitud.

Pese a que algunas personas le aconsejaron a la esclava que desistiera de la demanda, ella no estaba convencida de ello, comentándole a su defensor que solo lo haría si el gobernador de la provincia de Neiva se lo pedía. El expediente fue remitido a este funcionario pero él se abstuvo de proferir el fallo definitivo y encargó en esta misión al alcalde ordinario de la ciudad de La Plata, don Diego Falla Polanco.

En medio de una audiencia pública celebrada el 18 de enero de 1779, Falla Polanco dictó la correspondiente sentencia. A criterio de este funcionario, el defensor de la esclava no había comprobado la propuesta de libertad y, por lo tanto, no podía calificarse de justa la pretensión de dicha mulata. Así, entonces, ella y sus hijos debían permanecer en esclavitud, conminándola, además, a guardar "perpetuo silencio" y a no alegar nada sobre este mismo litigio. No obstante, como un acto de concesión se decidió absolverla del "merecido" castigo por ser infundadas sus aspiraciones y le fue, además, condonado el pago de las costas de la sumaria.

El caso fue revivido en 1786 tras una apelación elevada por María Encarnación ante las autoridades de Santa Fe. Allí retomó la defensa el procurador de pobres 
don José Joaquín Zapata y Porras, quien consideró que se había dictado auto definitivo en la ciudad de La Plata sin que se hubiesen cumplido cabalmente los trámites de derecho, todo esto debido al estado de miseria e indefensión de la demandante.

Por mandamiento de la Real Audiencia se ordenó a las justicias locales enviar de inmediato el expediente y se llamó al amo implicado, pues no se entendía cómo él no había ni siquiera contestado la demanda por los cargos que se le imputaban.

El procurador Zapata solicitó revocar el auto definitivo proferido en La Plata y amparar a María Encarnación en la libertad que pretendía. Esto lo sustentó en el hecho fundamental de que ella había cumplido con traer a este mundo los cinco hijos acordados y, por lo tanto, merecía el otorgamiento de dicho beneficio.

El amo había actuado con "malicia y fraude" al haber procedido a donar la esclava habiendo de por medio un ofrecimiento de libertad, reconociendo él mismo en la escritura de donación que lo hacía en retaliación a la demanda que la esclava había presentado. Siendo así, si consideraba Rodríguez injusta la pretensión de su servidora, debió primero responder a la demanda y después proceder a la donación. Así, entonces, con estos argumentos intentó Zapata demostrar que la devoción religiosa no fue precisamente el motivo que animó al amo a realizar el acto de donación.

Zapata censuró fuertemente la habilidad de Rodríguez de neutralizar la aspiración de libertad de su esclava y, por otro lado, asegurar que sus hijos quedaran en estado de esclavitud, lo cual comprobaba que su verdadera intención era aumentar considerablemente su capital. Dicho en otras palabras, se quería hacer énfasis en el hecho de que la donación efectuada no había sido graciosa sino remuneratoria.

Al juez local, entre tanto, se le criticó por haberse apresurado a dictar el fallo por "fuera de razón y justicia" sin antes haberlo remitido para que fuera revisado por instancias superiores en la ciudad de Santa Fe, pues era evidente su falta de conocimiento en materia de derecho.

Pese a todos los motivos expuestos por el procurador, finalmente la Real Audiencia decidió el 10 de abril de 1788 no aceptar el recurso de apelación y, en consecuencia, se confirmó el auto pronunciado por el alcalde Falla Polanco. Con esta decisión final queda claro cómo el amo logró salvar su honor y el de su esposa, mientras que la concubina resultó burlada y sometida junto con sus hijos a permanecer en estado de esclavitud. 
Hacia 1817, poco antes de morir, Alejo Prada de la parroquia de Piedecuesta en la provincia de Girón declaró, en presencia de su esposa legítima y de tres testigos más, su intención de liberar a sus dos hijas Feliciana y Juana, producto de sus amoríos con su esclava María de los Ángeles. A esto se le sumaba otro pequeño que la mulata llevaba en su vientre.

La viuda traicionada, doña Isabel de los Reyes, no controvirtió la valiente confesión de paternidad de su difunto marido, pero sí objetó la pretendida libertad de los esclavos al plantear la prioridad de cumplirles a varios acreedores. $\mathrm{Al}$ parecer, el amo había olvidado saldar más de 300 pesos de la dote de ella, una capellanía de 500 pesos junto con sus réditos de cuatro años y otros 200 pesos de deuda. Por lo tanto, su legado solo incluía una estancia, una pequeña casa de paja y 500 árboles de cacao sobre lo que se reconocía la capellanía indicada, 32 varas de tierra, medio solar y la esclava con sus dos vástagos, capital que sumado no bastaba para sufragar todas las cargas pendientes.

Se determinó entonces que los mulatos debían mantenerse al servicio de su señora hasta tanto no se formara el inventario y se averiguara el valor real de la manumisión otorgada por el testador. Al mismo tiempo, se trasladó el caso al síndico procurador general para que en calidad de protector de esclavos concurriera a evaluar las posibilidades de libertad (CDIHR-UIS, Archivo Judicial de Girón, caja 56, f. 539r).

\section{A manera de corolario}

Sin duda, la vida afectiva y familiar de la población esclava fue muy compleja y llena de obstáculos. Continuamente, este segmento social se vio amenazado por disposiciones legales que coartaban la libre elección de pareja y sintió inhibidas sus posibilidades de desarrollo conyugal y familiar tanto en sus relaciones intraetnia ${ }^{6}$ como en sus aventuras pasionales con otros grupos étnicos. Solo en las fugas, en los palenques y en todos aquellos espacios de vida clandestina, se puede decir que la comunidad negra contó con algún margen de libertad para unir su vida sin las habituales restricciones que le imponían su amo, el Gobierno colonial y la Iglesia.

La libertad se constituyó en un tema crucial en las historias de uniones sentimentales entre blancos y negras esclavas, así como también entre blancas y esclavos. Sin lugar a dudas, para el elemento esclavo fue tal vez la mayor aspiración no solo para la pareja sino para los hijos de estos vínculos sentimentales. De algún modo, este tipo de cruces interétnicos contribuyó al proceso de mestizaje que seguiría acentuándose con el paso del tiempo.

$6 \quad$ Sobre esta temática en particular, véase: (Pita, 2012, pp. 651-685). 
En particular, los casos descritos dejan al descubierto las inmensas complicaciones que debió afrontar la mujer esclava en sus relaciones amorosas con su propio amo, una situación en la cual su condición de género, su coloratura de piel y su estatus fueron factores decisivos en medio de una sociedad tradicionalmente patriarcal y fuertemente permeada por los principios morales pregonados por el catolicismo. Muy evidente era el estado de indefensión de estas mujeres ante sus propietarios, ante los familiares de estos y ante la justicia.

Aún con todas las dificultades, resulta realmente destacable el valor y la decisión con que la mujer esclava buscó reivindicar su derecho a la libertad y sus derechos sentimentales, derechos que, por todos los medios posibles, buscó extender a sus hijos. En ese sentido, ellas encontraron en los litigios una forma estratégica de ver atendidos sus clamores y de lograr ciertas concesiones sustentadas en la legislación imperante (Sherwin, 2004, p. 32).

Finalmente, vale decir que las historias incluidas en este artículo conducen a cuestionar el imaginario que la historia tradicional ha elaborado sobre el esclavo como un ser sumiso y pasivo. Por el contrario, tal como reitera también en su estudio la historiadora Juliana González Fernández, lo que queda al descubierto en los expedientes revisados es que en ciertas circunstancias estos individuos en estado de esclavitud decidieron aventurarse a luchar por sus destinos y a buscar espacios para expresar sus sentimientos y anhelos, lo cual se constituyó en un claro desafío al sistema de dominación vigente (2010, p. 47).

Hacia finales del siglo XVIII, cuando se tornó más compleja la sociedad colonial, fue más común encontrarse con entrecruzamientos entre blancos pobres y mulatas enriquecidas o de mulatos con blancas pobres, vínculos que aún con las acentuadas diferencias sociales y étnicas terminaron consolidándose ya que las precarias condiciones de vida obligaron a los integrantes del grupo social blanco a aceptar este tipo de unión como fórmula de supervivencia (Gutiérrez y Pineda, 1999, t. II, pp. 460-483).

Sin embargo, el hecho que las esclavas obtuvieran su libertad no era absoluta garantía para que sus romances con integrantes del grupo social blanco estuvieran exentos de señalamientos. Sobre estas negras manumisas seguiría pesando la estigmatización que regía contra sus antepasados esclavos.

En los convulsionados años del proceso de Independencia y en las primeras décadas de vida republicana, las esclavas continuarían su lucha por la libertad. Aunque durante estos periodos se ampliaron las posibilidades legales de acceder a la vida libre y se morigeraron las normas prohibitivas, a fin de cuentas, solo hasta 1851 esta comunidad vería finalmente cristalizado el sueño de la libertad definitiva. 
Roger Pita Pico

\section{Referencias bibliográficas}

Arboleda Niño, Juan Ignacio (2006). Entre la libertad y la sumisión. Estrategias de liberación de los esclavos en la gobernación de Popayán durante la Independencia, 1808-1830. Bogotá: Departamento de Historia de la Universidad de los Andes, Documento CESO n. ${ }^{\circ} 110$.

Archivo General de la Nación -AGN-. (Bogotá-Colombia). Fondos: Negros y Esclavos, Real Hacienda.

Archivo Histórico de Antioquia-AHA-. (Medellín-Colombia). Fondo Colonia, Grupo Negros y Esclavos.

Bermúdez, Suzy (1992). Hijas, esposas y amantes. Género, clase, etnia y edad en la historia de América Latina. Bogotá: Ediciones UniAndes.

Centro de Documentación e Investigación Histórico Regional, adscrito a la Universidad Industrial de Santander -CDIHR-UIS-. (Bucaramanga-Colombia). Fondos: Archivo Judicial de Girón, Archivo Notarial de Girón.

González Fernández, Juliana (2010). Seducción, ilegalidad y pasiones: las relaciones afectivas de los esclavos neogranadinos a finales de la Colonia. Bogotá: Tesis Pontificia Universidad Javeriana.

Escalante, Aquiles (1964). El negro en Colombia. Bogotá: Universidad Nacional.

Gutiérrez de Pineda, Virginia y Roberto Pineda Giraldo (1999). Miscegenación y Cultura en Colombia. Bogotá: Ediciones Uniandes, tomo II.

Jaramillo Uribe, Jaime (1989). Ensayos de Historia Social. Bogotá: Uniandes-Tercer Mundo Editores, tomo I.

Klein, Herbert (1986). La esclavitud africana en América Latina. Madrid: Alianza Editorial.

Konetzke, Richard (1958). Colección de documentos para la historia de la formación social de Hispanoamérica. Madrid: Consejo Superior de Investigaciones Científicas, V. 1, tomo 1.

Pita Pico, Roger (2012). La esclavitud de los sentimientos: vida familiar y afectiva de la población esclava en el nororiente del Nuevo Reino de Granada, 1720-1819. Revista de Indias, V. LXXII, n. ${ }^{\circ}$ 256, pp. 651-685.

Pita Pico, Roger (2015). Celos y rivalidades en los amoríos entre amos y negras esclavas en el Nuevo Reino de Granada en el periodo colonial. Afro-Hispanic Review, V. 34, n. ${ }^{\circ}$ 1, pp. 87-105.

Pita Pico, Roger (2015a). Los negros esclavos en Santander: desde la época de Conquista hasta las guerras de Independencia. Bucaramanga: Universidad Industrial de Santander.

Rodríguez, Pablo (1997). Sentimientos y vida familiar en el Nuevo Reino de Granada Siglo XVIII. Bogotá: Ariel.

Sherwin K., Bryant (2004). Enslaved Rebels, Fugitives and Litigants: The Resistance Continuum in Colonial Quito. Colonial Latin American Review, V. 13, n. ${ }^{\circ}$ 1, pp. 7-46.

Tovar Pinzón, Hermes (1994). Convocatoria al poder del Número. Santa Fe de Bogotá: Archivo General de la Nación.

Tovar Pinzón, Hermes (2004). La batalla de los sentidos, infidelidad adulterio y concubinato a fines de la Colonia. Bogotá: Fondo Cultural Cafetero. 